\title{
Research on Model Innovations of Vocal Teaching under the Background of Internet plus
}

\author{
Jing Sun \\ Academy of Music, Neijiang Normal University, Neijiang, 614000, China
}

Keywords: vocal teaching; music teaching; Internet plus

\begin{abstract}
Scientific and technological progress has a profound influence on the direction of the development of music teaching, and the teaching of vocal music is being transformed and upgraded based on "Internet plus". In the context of "Internet plus", vocal music teaching helps to stimulate interest of student, break through the limits of time and space and enrich teaching materials. Vocal music teachers should give full play to the role of the Internet to make the design innovation of teaching scheme, management innovation of teaching materials and mechanism innovation of teaching guarantee
\end{abstract}

\section{Introduction}

With the rapid development of internet technology, network teaching has become a new way for people to learn knowledge with the advantages of convenient use and wide resources [1]. The teaching of vocal music based on Internet technology has broken the limitation of time and space. It provides convenient conditions for those who love vocal music and want to learn vocal music. It has an important influence on the teaching and learning of vocal music and has become a new topic of attention and research. Vocal music learning is a process by which students learn vocal skills and make progress through vocal training. In this process, the teacher is the most important guide and the stick. It is the responsibility of every vocal teacher to guide the students to find a sound training sound by teaching the necessary sound skills of the students. In fact, teachers can not appear in every training of students. Therefore, students' autonomous learning is particularly important. Because the learners lack a keen ability to listen to themselves at first, they cannot accurately judge and grasp their voice state, so it is easy to go into misunderstandings when they practice themselves. Traditional vocal music learning is not free to choose locations and learning time. The teaching of traditional vocal music is face-to-face teaching, which is oral and mind oriented. Teachers should teach students according to their aptitude according to the different conditions and sound characteristics of each student. However, it is precisely because of the strict requirements of the teaching of vocal music to the actual teaching environment that many students who do not have the conditions to learn from the teachers have lost the opportunity to learn. In traditional vocal music teaching, teachers should not only make necessary guidance in the way of vocalization but also in the analysis of works and the grasp of singing style. In the original teaching mode, vocal music teachers' interpretation and analysis of works become the most important way for students to understand their works. To a certain extent, it restricts students' ability to understand the works [2].

\section{Advantages of Vocal Teaching under the Background of Internet plus}

\subsection{Stimulate Interest of Student.}

Traditional teaching is boring and students cannot concentrate on listening to the class at all [3]. Then through the combination of Internet multimedia teaching, the classroom will become lively, the vivid pictures in the video and the teaching will give the students a high concentration of energy. Naturally, the students will be more willing to learn sound. Music is a subject. Because of the 
large-scale enrollment expansion of colleges and universities, the faculty has not been directly proportional to growth. The student foundation is uneven, the classroom teaching time is limited, the teaching teacher cannot be able to fully consider every student in the classroom, so the students' self-study appears especially important after class, and the rich network resources can help students to better study independently. Vocal music teaching is different from that of other subjects. No matter it is vocal knowledge or vocal training, it is relatively abstract. Once a week, vocal music classes are far from enough to enhance learners' memory of vocal state and feeling. Through watching the video teaching of teachers with rich teaching experience on the Internet, it can be compared with the teaching of famous teachers on the Internet to strengthen their understanding of the sound state and feeling of singing. By communicating with teachers or learning from other people's singing in class, we can understand the requirements of correct sound more comprehensively and learn from the strengths of others to enrich themselves in all aspects and improve the comprehensive performance of singing. Through the integration of the Internet and multimedia into the teaching of vocal music, the students' various sensory systems can be mobilized. Multimedia and Internet technology can collect all kinds of video and pictures and so on. This will become more infectious and can also improve students' interest in learning. Through video images, students can clearly understand how to vocalizations, how to learn vocal music and how to learn vocal music well.

\subsection{Break through the Limits of Time and Space.}

Due to the particularity of the vocal music subject and the characteristics of every vocal learner, the teaching of vocal music continues the traditional teaching method [4]. The requirements of the teaching conditions, the invisible in a barrier between teachers and students, so that many vocal enthusiasts are prohibitive, there is no teacher after class do not know how to practice the situation. The new teaching method of network vocal music teaching can solve this problem. Using the forum to carry out online interactive learning and communication between teachers and students, students can not only absorb many professional vocal knowledges to the maximum extent, but also get the help of professional teachers and other learners when they meet the difficult problems that cannot be overcome and listen to a wide range of opinions or suggestions. It can also learn directly through the Internet online vocal teaching in special voice and video chat rooms. In the primary stage of vocal music learning, how to measure and judge the sound condition or singing level objectively and correctly, and how to avoid the narrow thinking by the help of the Internet vocal music teaching. Students often cannot fully face their own singing state, the understanding of the concept of singing will also have a great deviation. Teachers should use multimedia in the teaching, play video teaching of vocal music educators at home and abroad on the network, open students' vision and ideas, make students think and look for their own performance. Sing for yourself and achieve good results. Vocal music teaching should also try to make use of the convenience brought by network resources, so that the network computer can play a role in vocal music teaching as a teaching medium.

\subsection{Enrich Teaching Materials.}

Modern information technology provides learners with extremely rich learning resources. Online education information resources are divided into eight categories: electronic books, electronic periodicals, databases, virtual libraries, electronic encyclopedia, educational websites, virtual software libraries and electronic forums. These resources show us in different forms. Under the network background, more and more educators are searching the teaching materials through the Internet to enrich their teaching contents. Due to the rapid update of network information, learners can understand the academic trends at home and abroad in time and can download the music audio and visual materials and documents that they need or interest through the network. The Internet can also provide learners with novel teaching ideas, innovative teaching models and substantial teaching contents. Students find different learning resources according to their different learning needs and contribute them to communicate with others. The maximum sharing of network teaching resources can not only satisfy students' learning needs at different levels, but also satisfy students' choice of music resources that they are interested in. Therefore, the full use of network resources to carry out 
teaching is beneficial to the realization of individualized teaching. It is of great significance to train the learners' consciousness of self-study and competition, to stimulate the potential of the learners and to develop the comprehensive quality of the learners. Rational and effective use of network resources to broaden our horizons and learn new tracks is another convenient way for the Internet to learn vocal music. The network can provide different versions of music information such as the original singing, the reversion and so on. Learners can not only learn to sing melodies quickly, but also help in many aspects such as performing songs, experiencing emotions and singing. The application of the Internet in vocal music teaching has proved that as a kind of teaching media, it can not only improve the efficiency of vocal music teaching, but also improve the quality of vocal music teaching.

\section{Model Innovations of Vocal Teaching under the Background of Internet plus}

\subsection{Design Innovation of Teaching Scheme.}

The application of the teaching method of vocal music information is to analyze the potential factors that affect the students' learning under the premise of the students' specific motivation and find out the effective ways to improve the students' learning interest according to the scientific analysis results and make a teaching plan that meets the students' learning situation. The design of the teaching plan should be divided into specific training programs and specific implementation plans. Using information teaching system to meet the needs of students' specific learning. At the same time, on the premise of satisfying the basic teaching, we can divide the students' recent learning and development level through the training program, make an accurate analysis of the students' learning performance in the recent stage, carry out the accurate qualitative analysis of the academic achievements, and implement the implementation plan according to the results of the analysis, and plan the middle school students in the nearest learning level. What kind of learning objectives should be achieved, what kind of learning task is completed, and a corresponding incentive mechanism to stimulate students, maintain the enthusiasm of the students, fully mobilize the students' learning personality, help students form a good learning consciousness, understand the art principles and knowledge principles of vocal music, and grasp the correct skills. Skillfully and methods, give full play to the students' personality, let the students' interest guide the active completion of the learning task, form a high understanding of the principle of art, and master the space of their own learning and development. At the same time, the teaching method of information is an effective way to realize the high quality vocal music teaching based on the interest of students' learning and the different vocal music teaching resources. It can meet the needs of the modern teaching according to the students' interest starting point, fully enhance the students' artistic vision and promote the students to form the correct values.

\subsection{Management Innovation of Teaching Materials.}

The organic integration of college vocal music teaching and Internet technology should form an integrated and information-based resource teaching model. It is necessary to integrate the integrated information management into the construction of vocal music teaching platform and improve the overall teaching efficiency in an all-round way. Therefore, in the process of the construction of the vocal music information platform, on the one hand, we should take information technology as the technical guidance, develop the teaching system of vocal music information in an all-round way and implement the electronic information interactive teaching to meet the demand of teaching information supply. In addition, in the integrated management process of modern vocal music teaching, the computer information technology is fully utilized to realize the storage, sharing and interaction of the file information. Through the information management system, the original complicated teaching program work can be easily operated through the information system, and the seamless docking of various teaching links in the hospital is realized. Fully meet the needs of automation and integration of information and promote the modernization of university learning platform. In addition, the age of the Internet is an information era, a representative form of social 
progress, with the continuous expansion of the scale of modern music colleges and universities, and the continuous improvement of the teaching level, the information technology has brought great influence to the modern learning system. At present, all the music colleges and universities in our country are fully engaged in the information integration construction mode, strengthen the construction of their own teaching information mode, innovate their own service mode, constantly improve their service level, fundamentally improve their own form of information service, and establish a full and efficient teaching platform for vocal music for a wide range. Master students are used to improve the level of vocal music teaching. The interactive form of digital resources goes beyond the technical ability of vocal music teaching and the way of interaction of information resources has fundamentally changed. Therefore, vocal music departments in universities should rely on the advantages of information technology to strengthen the integration of curriculum data resources and classify information resources.

\subsection{Mechanism Innovation of Teaching Guarantee.}

It is very important to build corresponding information guarantee mechanism in vocal music teaching platform. The establishment of information mechanism is not only to meet the needs of students to acquire learning resources, but also to establish an effective information service system to ensure the stable operation of the platform through the establishment of platform service architecture. We should build a complete and controllable information screening system based on the frequency of the use of resource information and the scope of the use of digital resources information. The information users of the illegal intrusion system should be blocked and screened in time to prevent the information data from leaking. In addition, the establishment of the information security system should be based on the principle of digital resource control, to deal with the information of teaching resources, so that the course digital information is in a state of control at any time, to meet the needs of the students' diversified teaching information inquiry, and to ensure that the information system of the curriculum resources is not affected by the weather and the region. Ringing, data transmission can be carried out in real time. At the same time, the construction of the construction of the curriculum information service architecture should also consider the non-repudiation of the information of the curriculum resources, because there are various forms of data change in the process of the timely communication and transmission of the digital resources information. In the process of use, the actual identity of the users of the curriculum information resources is determined and the resource information is guaranteed. The use value allows students to use curriculum resources efficiently based on fast access to curriculum resources, to ensure the stable operation of the teaching system, so that students can learn vocal knowledge in a more stable and safe information environment and improve their theoretical cognition. A special and open website should be set up to compile and publish the mature works in vocal practice and vocal music teaching activities. It not only expands the social influence of colleges and universities, but also encourages students to grow faster.

\section{Conclusion}

The internet has expanded the materials of vocal music teaching with its unique advantages and has provided a convenient learning condition for vocal fans. Under the background of "Internet plus", many kinds of innovation of the vocal teaching models can be achieved. Based on traditional teaching models, vocal music teachers should get the latest information through the network so that students can learn more and better to cultivate the students' ability to study independently.

\section{References}

[1] Li Shan. On the Thinking and Exploration of “ Internet +” Music- A Study from Music Perspective [J]. Journal of Beijing Union University (Humanities and Social Sciences), 2016, 14(1): 73-78.

[2] Song Yulin. Research on the We MediaTransmis s ion of Elegant Mus ic Under "Internet Plus” [J]. 
Journal of Xingyi Normal University for Nationalities, 2017(6): 58-61.

[3] Liu Yangjun. The Development and Reform of Modern Music under the Internet + Mode [J]. Journal of Xinjiang University of the Arts, 2018, 16(1): 29-33.

[4] Wang Hanxi, Chen Chong, Zhang Yanping. The Key Technology "Internet Plus Digital Music" Facing [J]. Journal of Wuhan University of Technology, 2017, 39(3): 97-102. 